\title{
Ultra-Wideband Antenna Using CPW Resonators for Dual-Band Notched Characteristic
}

\author{
Y. F. Weng, S. W. Cheung and T. I. Yuk \\ Department of Electrical and Electronic Engineering \\ The University of Hong Kong \\ Hong Kong \\ E-mail: [yfweng, swcheung, tiyuk]@eee.hku.hk
}

\begin{abstract}
This paper presents the design and results of a compact Ultrawideband (UWB) monopole antenna with a dualband notched characteristic. The antenna consists of a semicircular radiator and a dual-coplanar-waveguide (CPW) resonator to produce two notched bands at the center frequencies of 3.5 and $5.5 \mathrm{GHz}$ in the UWB region. The computer simulation results of the Voltage-Standing-Wave Ratio (VSWR), radiation pattern and peak gain of the antenna agree well with the measurements.
\end{abstract}

Keywords - Coplanar Waveguide Resonator, monopole antenna, ultrawideband (UWB) antenna, band notched.

\section{INTRODUCTION}

In 2002, the US-FCC assigned the frequency band of 3.1$10.6 \mathrm{GHz}$ for UWB communication systems [1]. The advantages of the Ultrawideband (UWB) communication system mainly include: high data rate (more than $100 \mathrm{Mb} / \mathrm{s}$ ) for short ranges, low power consumption and easy connection among a large number of multimedia devices such as PCs, high-definition TVs, digital cameras, etc. As a result, the UWB is attracting considerable interests and research activities in recent years. Compact size, low cost and good performance, e.g. non-dispersive, omnidirectional radiation pattern and relatively uniform gain, are all important criteria for UWB antennas and this have brought many opportunities and challenges to the antenna designers.

In the US-FCC allocation of frequency band for UWB applications, there are already several other existing communication systems, e.g. IEEE 802.11a WLAN in the frequency band of $5.15-5.825 \mathrm{GHz}$ and the IEEE 802.16 WiMax mainly operating in frequency band of 3.3-3.6 GHz. These systems may potentially interfere with the UWB systems. Thus UWB antennas with band-notched characteristic are necessary to ease this potential problem. Different antenna design methods have been proposed to produce the bandnotched characteristic in the UWB band [2-10]. Among these designs, etching different kinds of slots on the patch or ground of the antennas is most often used [2-4]. Other methods include adding parasitic elements, using folded strips to the antennas [5] and etching split-ring resonator (SRR) or complementary splitring resonator (CSRR) on the radiator [6-8]. Embedding resonated cell in microstrip line or coplanar waveguide can also effectively filter the undesired bands [9-10], but the antennas have only one notched band from $5.15 \mathrm{GHz}$ to $5.85 \mathrm{GHz}$.

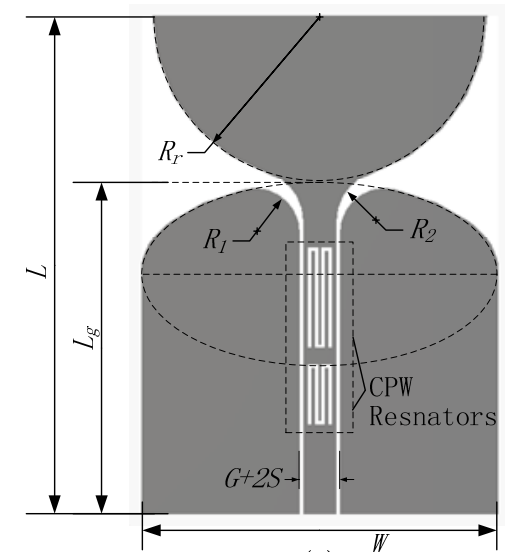

(a)

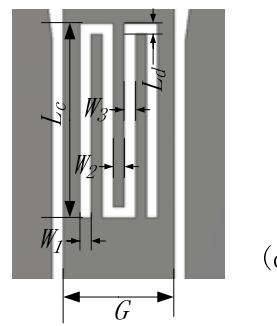

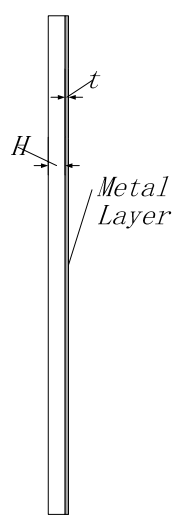

(b)
Fig. 1 (a) Layout and (b) side view of antenna with single CPW resonator, and (c) layout of CPW resonator.

In this paper, a dual-band CPW resonator consisting of two $\mathrm{CPW}$ resonators connected in series is proposed to achieve a dual-band notched characteristic for an UWB antenna. An UWB antenna with the dual-band CPW is designed and studied by using the computer simulation tool CST MWS 2009 [13] and the Satimo Starlab measurement system [14]. Results show that the dual-band notched antenna can operate in a band from $2.16 \mathrm{GHz}$ to over $12 \mathrm{GHz}$ with Voltage-Standing-Wave Ratio (VSWR) $\leq 2$ and the radiation pattern is almost omnidirectional over the entire UWB band. 


\section{ANTENNA DESIGN}

\section{Structure of antenna}

In our design, we propose to use a semi-circular radiator fed by a $50-\Omega$ CPW to minimize the antenna size for applications in wireless devices. Figure 1 shows the layout of our design which is fabricated on a Rogers PCB, RO4350B, with a transverse dimension of $32 \mathrm{~mm} \times 35 \mathrm{~mm}$ and having a relative dielectric constant $\varepsilon_{r}=3.48$, thickness $0.762 \mathrm{~mm}$ and loss tangent 0.0037 for the substrate. The width of the CPW, $G$, and the distance between the feed line and ground, $S$, are $3 \mathrm{~mm}$ and $0.3 \mathrm{~mm}$, respectively, in order to have a characteristic impedence of $50 \Omega$. The ground plate is a rectangle plus a half ellipse with a ratio of 0.5 to reduce the beam tilt of the antenna [9]. The small area connecting the CPW and the semi-circular radiator is critical for impedance matching and so is smoothed by using two arc shapes with a radius of $R_{1}$ and $R_{2}$. Detail dimensions of the single notched band antenna are listed in Table 1.

TABLE I. ANTENNA DIMENSIONS

\begin{tabular}{cccc}
\hline Parameter & Value $(\mathbf{m m})$ & Parameter & Value $(\mathbf{m m})$ \\
\hline$L$ & 35 & $L_{d}$ & 0.3 \\
$W$ & 32 & $W_{1}$ & 0.3 \\
$L_{g}$ & 20 & $W_{2}$ & 0.3 \\
$R_{r}$ & 15 & $W_{3}$ & 0.3 \\
$R_{1}$ & 4 & $G$ & 3 \\
$R_{2}$ & 4.5 & $S$ & 0.3 \\
$t$ & 0.0035 & $L_{c}{ }^{a}$ & 5.3 \\
$H$ & 0.762 & $L_{c}{ }^{b}$ & 9 \\
\hline & & a. & Notched band at $5.5 \mathrm{GHz}$ \\
& & b. & Notched band at $3.5 \mathrm{GHz}$
\end{tabular}

\section{Dual-band CPW Resonator}

CPW resonator is a basic component in CPW circuits. Different types of $\lambda / 2$-open-ended CPW resonators and $\lambda / 4$ CPW resonators have been used to design bandstop filters [1314]. However, the sizes of these types of CPW resonators are too large and so difficult to integrate into the RF front ends of wireless devices. Here we propose a new structure of CPW resonator with a much smaller size as shown in Fig. 1 (c). One of the CPW resonator is etched with a distance of $8 \mathrm{~mm}$ from the bottom of ground. The separation between the two CPW resonators is $2 \mathrm{~mm}$. The resonance of the CPW resonator is determined by the length $L_{c}$ and the small gap $L_{d}$ as shown in Fig. 1(c).

Simulation results on the VSWR with different values of $L_{c}$ and $L_{d}$ in the CPW resonator using CST MWS 2009 [11] are shown in Figs. 2 and 3, respectively. It can be seen that the resonance frequency varies with $L_{d}$ and $L_{c}$, but the VSWR values in the other UWB band remain almost the same. This property provides a great freedom to the designers to vary the frequency of the notched band for the antennas. Thus in our proposed antenna, we use two CPW resonators connected in series, a dual-band CPW resonator, as shown in Fig. 1 to create two different notched bands.

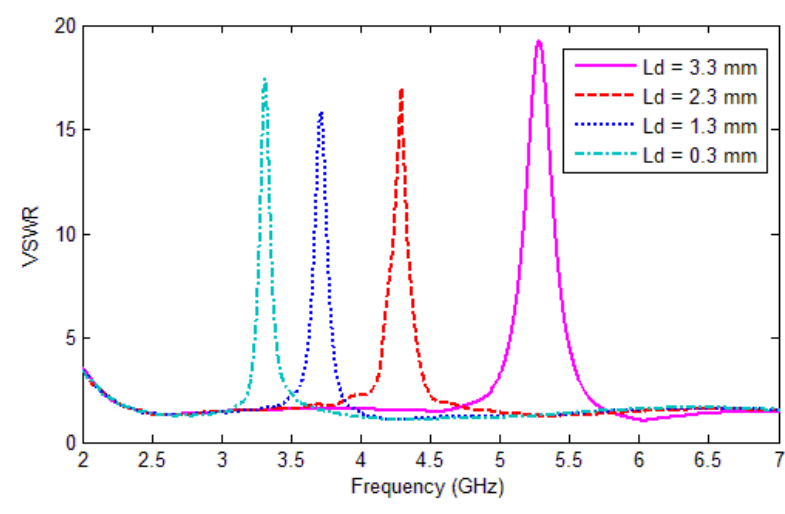

Fig. 2 VSWR for different values of $L_{d}$, with $L_{c}=9 \mathrm{~mm}, W_{1}=W_{2}=W_{3}=S=$ $0.3 \mathrm{~mm}$ and $G=3 \mathrm{~mm}$

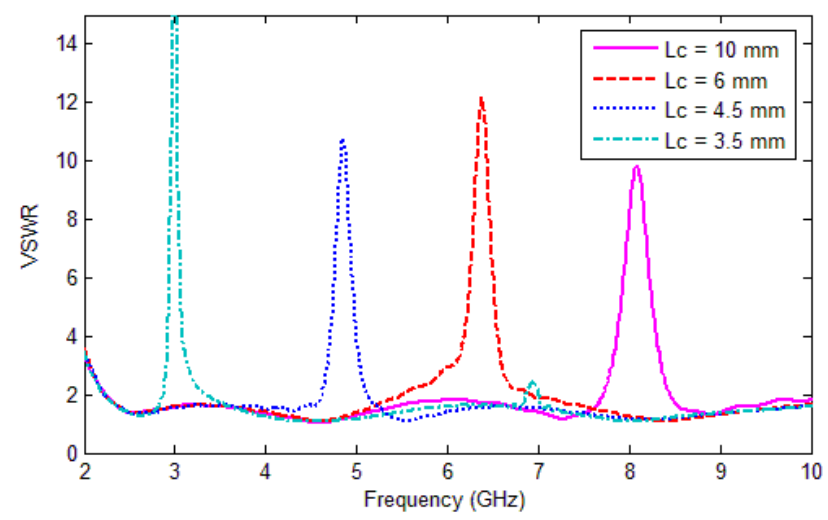

Fig. 3 VSWR for different values of $L_{c}$, with $L_{d}=W_{1}=W_{2}=W_{3}=S=0.3 \mathrm{~mm}$ and $G=3 \mathrm{~mm}$.

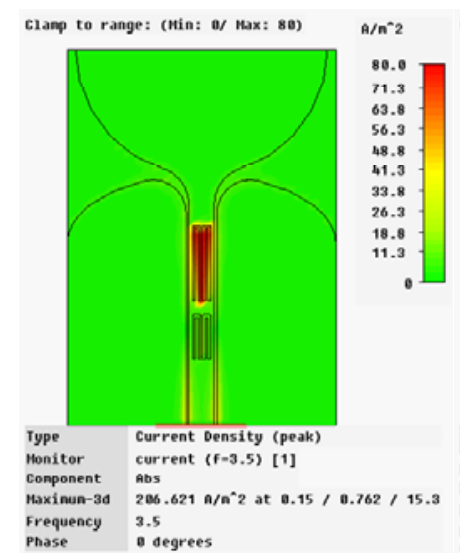

(a)

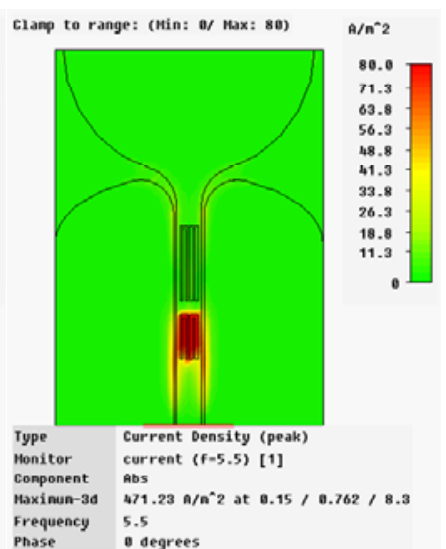

(b)
Fig. 4 Distribution of surface current at (a) $3.5 \mathrm{GHz}$, (b) $5.5 \mathrm{GHz}$.

To better understand the antenna operation, the distributions of surface current on the antenna at the notched frequencies have been studied using CST MWS 2009 and results are shown in Fig. 4. At $3.5 \mathrm{GHz}$ and $5.5 \mathrm{GHz}$, Figs. 4(a) and 4(b) show that the energies are confined in the upper and lower CPW 
resonators, respectively, and are much higher than that in the main radiation element and do not get radiated.

\section{RESULTS AND DisCUSSIONS.}

The final designs of the antennas, with and without the dual-band CPW resonator (for the notched bands centered at $3.5 \mathrm{GHz}$ and $5.5 \mathrm{GHz}$ ), have been fabricated using Rogers PCBs, RO4305B, as shown in Fig. 5. The VSWR and Peak Gain across the UWB band, and the Radiation Patterns at 4.5 $\mathrm{GHz}, 6 \mathrm{GHz}$ and $9 \mathrm{GHz}$ have been studied by using CST MWS 2009 and measured using the Satimo Starlab measurement system.

The simulation and measurement results of VSWR in Fig. 6 show that there are two notched bands, from $3.26 \mathrm{GHz}$ to 3.75 $\mathrm{GHz}$ and $5.02 \mathrm{GHz}$ to $5.90 \mathrm{GHz}$, across the UWB band. The VSWR is substantially higher (VSWR $>2$ ) in the notched bands. The results also show that the antenna can work in a frequency band from $2.16 \mathrm{GHz}$ to over $12 \mathrm{GHz}$ for VSWR $\leq 2$ which fully satisfy the UWB requirement.

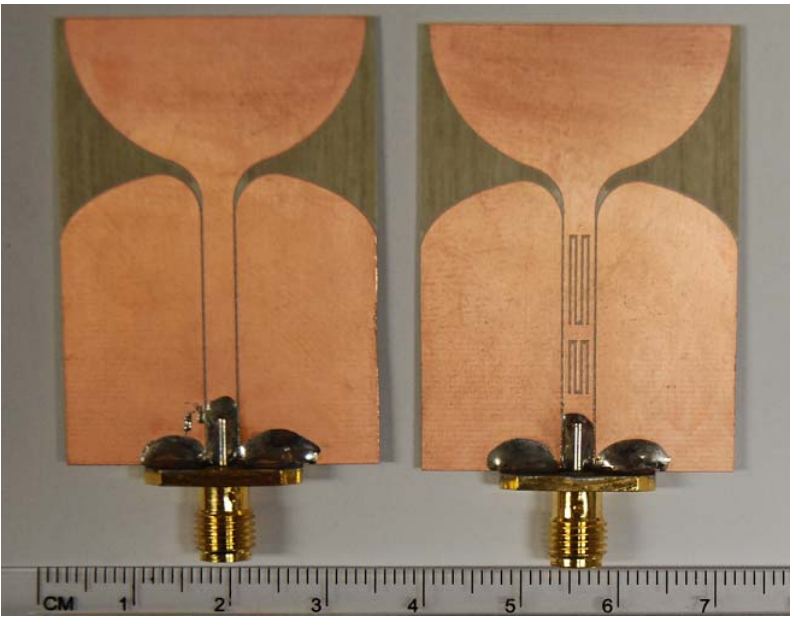

Fig. 5 Photograph of the proposed antennas without and with dual-band CPW resonator for dual-notched bands at $3.5 \mathrm{GHz}$ and $5.5 \mathrm{GHz}$.

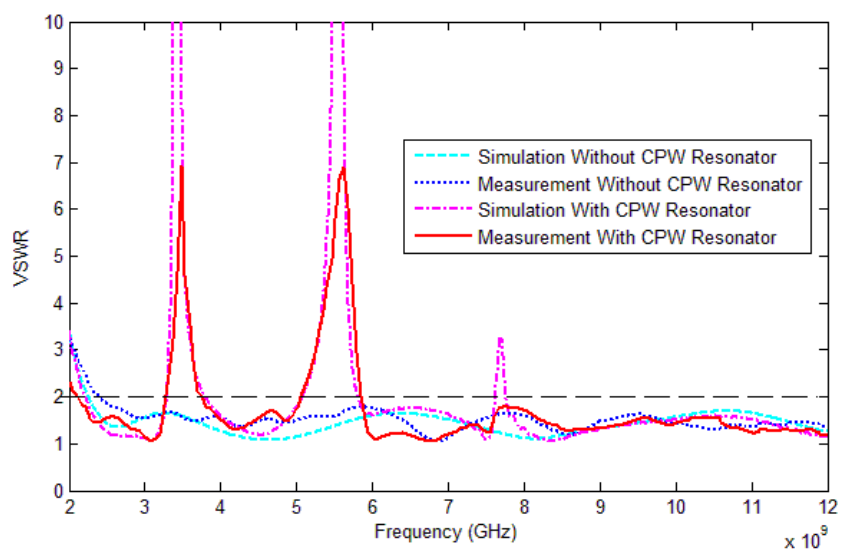

Fig. 6 Simulated and measured VSWR of antenna with and without dual-band CPW resonator.
The simulated and measured radiation patterns of the antenna with the dual-band CPW resonator, at the frequencies of $4.5 \mathrm{GHz}, 6 \mathrm{GHz}$ and $9 \mathrm{GHz}$ and in three important cuts, i.e., in the $x-z, y-z, x-y$ planes, are shown in Fig. 7. It can be seen that the measured radiation patterns agree well with the simulated results. For UWB applications, omnidirectional radiation pattern is normally preferred (i.e., in the $\mathrm{x}-\mathrm{y}$ plane). The results of Fig. 7 show that the radiation patterns at all of the three frequencies satisfy this requirement well.

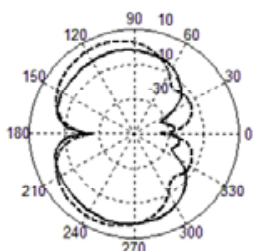

(a)

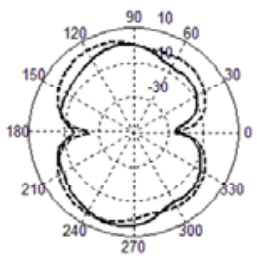

(d)

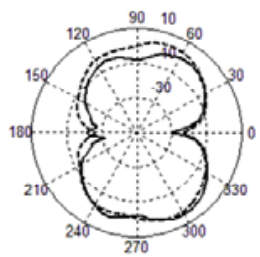

(g)

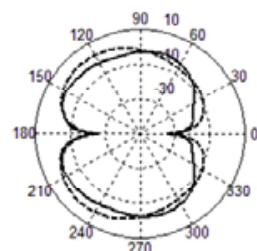

(b)

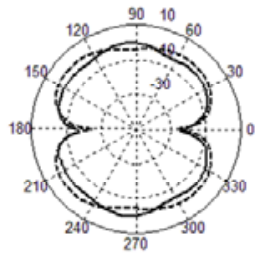

(e)

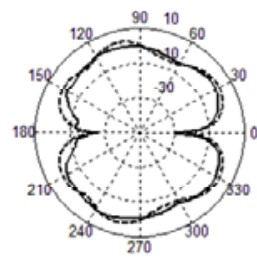

(h)

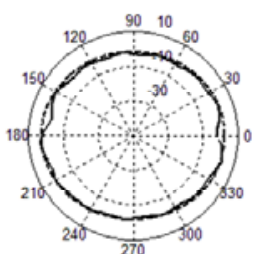

(c)

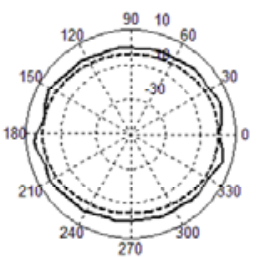

(f)

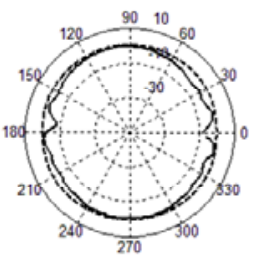

(i)
Fig. 7 Simulated and measured radiation patterns with dual-band CPW resonator. Solid lines and dash lines are measured and simulated results, respectively. (a) $4.5 \mathrm{GHz}$ in $\mathrm{x}-\mathrm{z}$ plane; (b) $4.5 \mathrm{GHz}$ in y-z plane; (c) $4.5 \mathrm{GHz}$ in $\mathrm{x}-\mathrm{y}$ plane; (d) $6 \mathrm{GHz}$ in $\mathrm{x}-\mathrm{z}$ plane; (e) $6 \mathrm{GHz}$ in $\mathrm{y}-\mathrm{z}$ plane; (f) $6 \mathrm{GHz}$ in $\mathrm{x}-\mathrm{y}$ plane; (g) $9 \mathrm{GHz}$ in $\mathrm{x}-\mathrm{z}$ plane; (h) $9 \mathrm{GHz}$ in $\mathrm{y}-\mathrm{z}$ plane; and (i) $9 \mathrm{GHz}$ in $\mathrm{x}-\mathrm{y}$ plane.

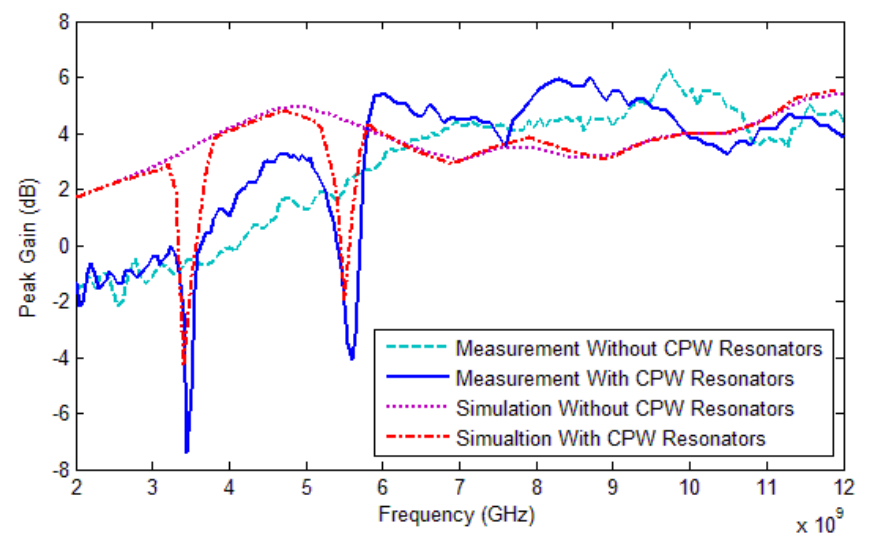

Fig. 8 Simulated and measured peak gain with and without dual-band CPW resonator. 
The simulated and measured peak gains of the antenna, with and without the dual-band CPW resonator, in the UWB band are shown in Fig. 8. With the dual-band CPW resonator, the simulation results show that the peak gains around the center frequencies of $3.5 \mathrm{GHz}$ in the WiMax band and $5.5 \mathrm{GHz}$ in the WLAN band drop drastically by about 10 and $8 \mathrm{~dB}$, respectively. While the measured results show the drops are about $6 \mathrm{~dB}$ in these two notches. At other frequencies (i.e., from $6 \mathrm{GHz}$ to $12 \mathrm{GHz}$ ), the peak gains are in the range from 3 to $6 \mathrm{~dB}$ which are higher than those of the antenna without the dual-band $\mathrm{CPW}$ resonator.

\section{CONCLUSIONS}

In this paper, we have proposed and presented the design of a small-size CPW-fed monopole antenna that exhibits dual band-notched characteristic at the center frequency of 3.5 and $5.5 \mathrm{GHz}$ in the UWB band. The planar monopole antenna consists of a semi-circular shape as the primary radiation element and a dual-band CWP resonator to produce a deep notch at $3.5 \mathrm{GHz}$ of the WiMax band and another deep notch at $5.5 \mathrm{GHz}$ of the WLAN band. Simulated and measured results have shown great agreements. Results have shown that the antenna pattern is almost omnidirectional in the UWB band and the peak gains are quite satisfactory.

\section{REFERENCES}

[1] "Federal Communications Commission Revision of Part 15 of the Commission's Rules Regarding Ultra-Wideband Transmission Systems," FCC, 2002, First Report and Order FCC, 02.V48.
[2] W. Choi, K. Chung, J. Jung and J. Choi, "Compact ultra-wideband printed antenna with band-rejection characteristic," Electron. Lett., vol. 41, no. 18, pp.s 990-991, Sep. 2005.

[3] K. Chawanonphithak, C. Phongcharoenpanich, S. Kosulvit and M.Krairiksh, "5.8 GHz notched UWB bidirectional elliptical ring antennaexcited by circular monopole with curved slot," in Proc. AsiaPacificMicrowave Conf., pp. 653-656, Dec. 2007.

[4] Y. Kim and D.H. Kim, "CPW-fed planar ultra wideband antenna having a frequency band notch function," Electron. Lett., vol. 40, no. 7, pp. 403-405, Apr. 2004.

[5] T. G. Ma and S. J. Wu, "Ultrawideband band-notched folded strip monopole antenna," IEEE Trans. Antennas Propag., vol. 55, no. 9, pp. 2473-2479, Sep. 2007.

[6] J. Kim, C. S. Cho and J. W. Lee, "5.2 GHz notched ultra-wideband antenna using slot-type SRR," Electron. Lett., vol. 42, no. 6, pp. 315316, Mar. 2006.

[7] T.N. C and M.C. W, "Band-Notched Design for UWB Antennas," IEEE Antennas and Wireless Progag Lett, vol. 7, pp. 636-640, 2008.

[8] Y. Zhang, W. Hong, C. Yu, Z-Q. Kuai, Y-D. Don and J-Y. Zhou, "Planar Ultrawideband Antennas With Multiple Notched Bands Based on Etched Slots on the Patch and/or Split Ring Resonators on the Feed Line,” IEEE Trans. Antennas Propag, vol. 56, pp. 3063, Sep. 2008.

[9] S.W. Qu, J.L. Li and Q. Xue, “A Band-Notched Ultrawideband Printed Monopole Antenna," IEEE Antennas and Wireless Progag Lett, vol. 5, pp. 495-498, 2006.

[10] Y. Ding, G.M. Wang and J.G. Liang, "Compact Band-Notched UltraWideband Printed Antenna," Microwave and Optical Technology Letters, vol. 49,pp. 2686-2689, Nov, 2007.

[11] Availanle on: http://www.cst.com.

[12] Available on: http://www.satimo.fr/eng/index.php?categoryid=141.

[13] M. Houdart, "Coplanar Lines: Application to Broadband Microwave Integrated Circuits," Proceedings, $6^{\text {th }}$ European Microwave Conference, Rome, Italy, pp. 49-53, 1976.

[14] X.Y. Wu, I. Awai, Z.Y. Yan, K. Wada and T. Moriyoshi, "QUALITY FACTORS OF COPLANAR WAVEGUIDE RESONATORS,” Microwave Conference 1999 Asia Pacific, vol. 3, pp. 670-673, 1999. 